\title{
Automatic Flux Coating System
}

\author{
T. A. Selvan ${ }^{1 *}$, A. Viswanathan ${ }^{2}$, S. Sneha ${ }^{1}$ and S. Madhankumar ${ }^{1}$ \\ 'Department of Mechatronics Engineering, Sri Krishna College of Engineering and Technology, \\ Kuniamuthur - 641008, Coimbatore, Tamil Nadu, India; \\ selvan@skcet.ac.in, snehas@skcet.ac.in,madhankumars@skcet.ac.in \\ 2SNS college of Technology, Vazhiyampalayam, Coimbatore - 641035, Tamil Nadu, India; deansandh@snsct.org
}

\begin{abstract}
Background/ Objective: To design and fabricate an automatic spray coating system that can help in the industries. Handling hazardous chemicals like fluxes in hands is a serious issue in today's manufacturing units. Methods: The study focuses on the early stages and the preliminary design that, how the flux mixture is coated on the aluminium plates with the air atomizer and air blower applications. It also describes about the input feed given by the pneumatic actuator and the serial movement of the work piece in the frame of the setup. Findings: The overview of this paper also bothers about compact design for commuting the circular plates without using the conveyor system, instead by the regular push by the pneumatic actuator at pre defined intervals. Applications: This concept of automation in the flux application is substituting the 30 years of conventional, human operation in the industry.
\end{abstract}

Keywords: Atomized Sprayer, Brazing, Flux, Heat Gun and Manual Assistance

\section{Introduction}

The theme is about the automated flux coating of aluminum plates which is carried out prior to the brazing operation in the industry to avoid the intervention of manual assistance for handling the flux chemicals in hand. The uncoated aluminum plates are loaded in the input stacker ${ }^{1}$, which has semi-circular openings in the bottom. The pneumatic actuator which is placed adjacent to the stacker pushes the circular plates in to the frame, which contains the air atomizer chamber. There, the flux mixture gets coated on both sides of the aluminum plates. When the similar operation is carried under regular intervals, the first plate is pushed by the succeeding plates and moves forward. Eventually, the first plates crosses the heating chamber, where hot air blowers are employed for drying operations and then the flux coated plates are collected as an output of the operation ${ }^{2}$. This serial operation with the help of pneumatic actuator continues till all the aluminum plates get flux coating. This concept of automation in the flux application is substituting the 30 years of conventional, human operation in the industry ${ }^{3,4}$.

\section{Overall Structure of the System}

The entire system in Figures 1-2 contains the following components:

1. Aluminium plate hopper

2. Plate holder,

3. Hot air blower,

4. Stirrer,

5. Motor (stirrer),

6. Tank,

${ }^{*}$ Author for correspondence 


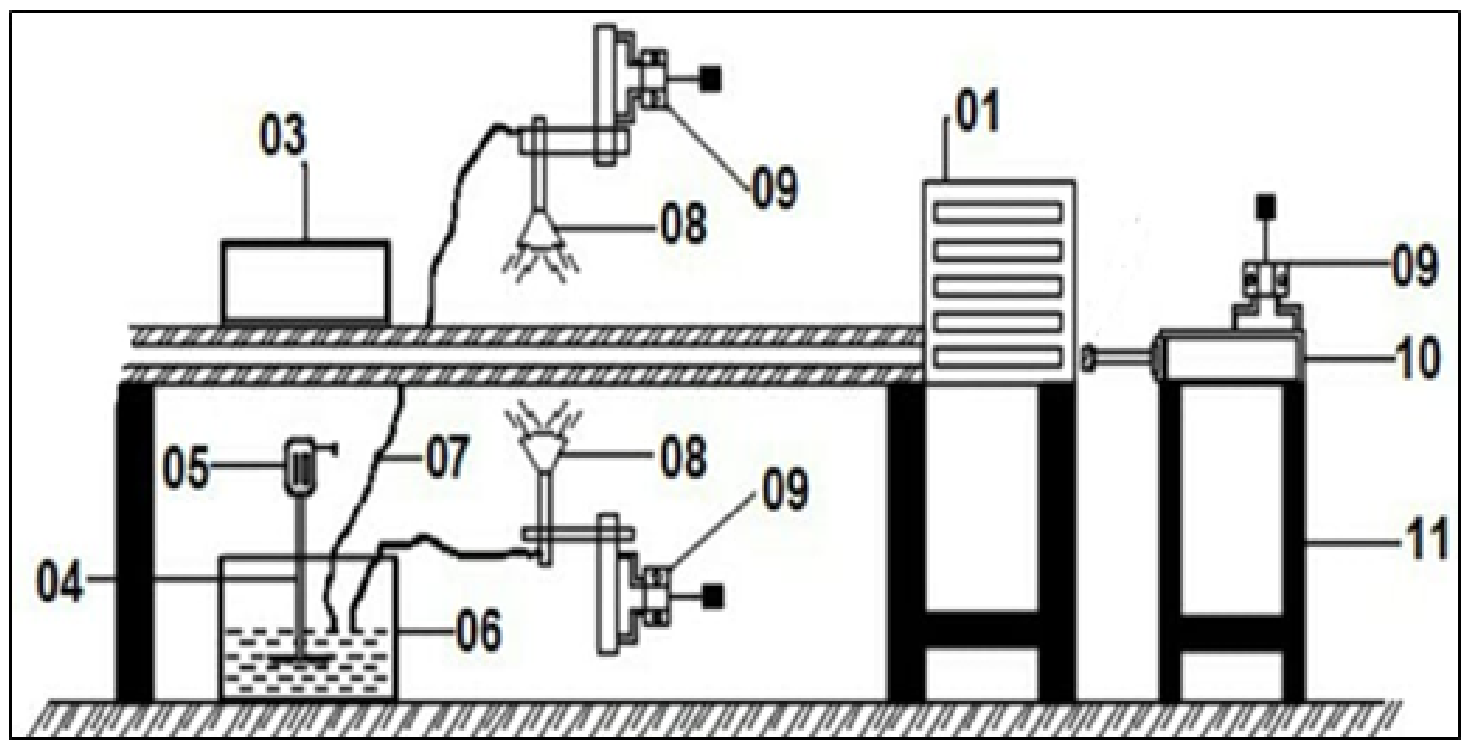

Figure 1. Side view of the flux coating system.

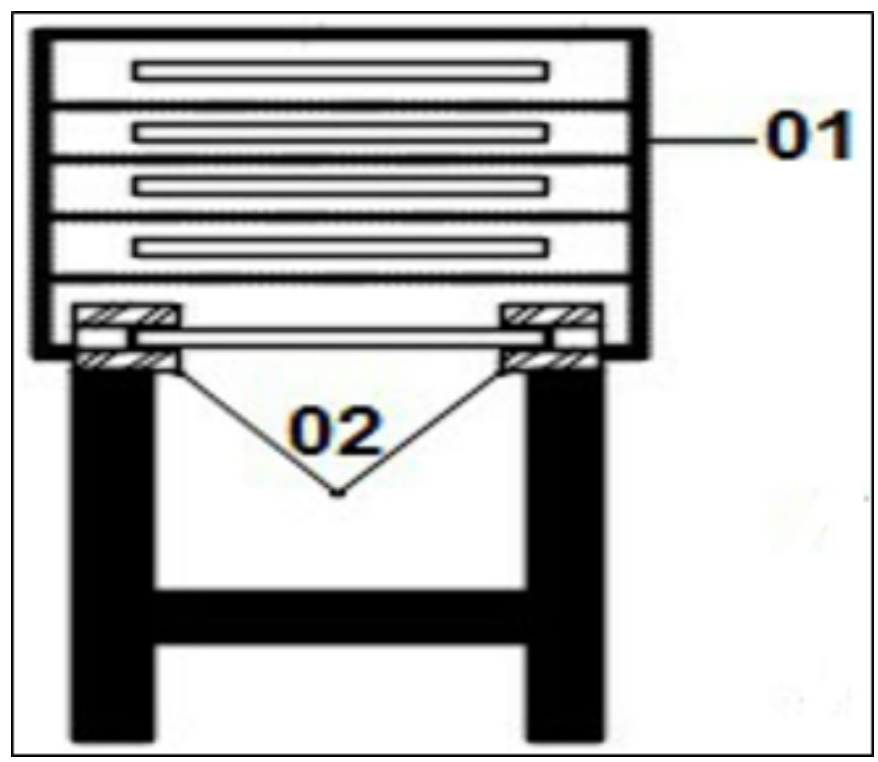

Figure 2. Front view of the flux coating system.

7. Paint flow tube,

8. Top and bottom air atomizer,

9. Solenoid valve,

10. Pneumatic actuator, and

11. Frame.

\section{Systematic Movement of the Circular Aluminium Plates}

The uncoated input plates are arranged in the plate hopper, from which the constant feed is given by the pneumatic actuators. The circular plate is taken and pushed in to 


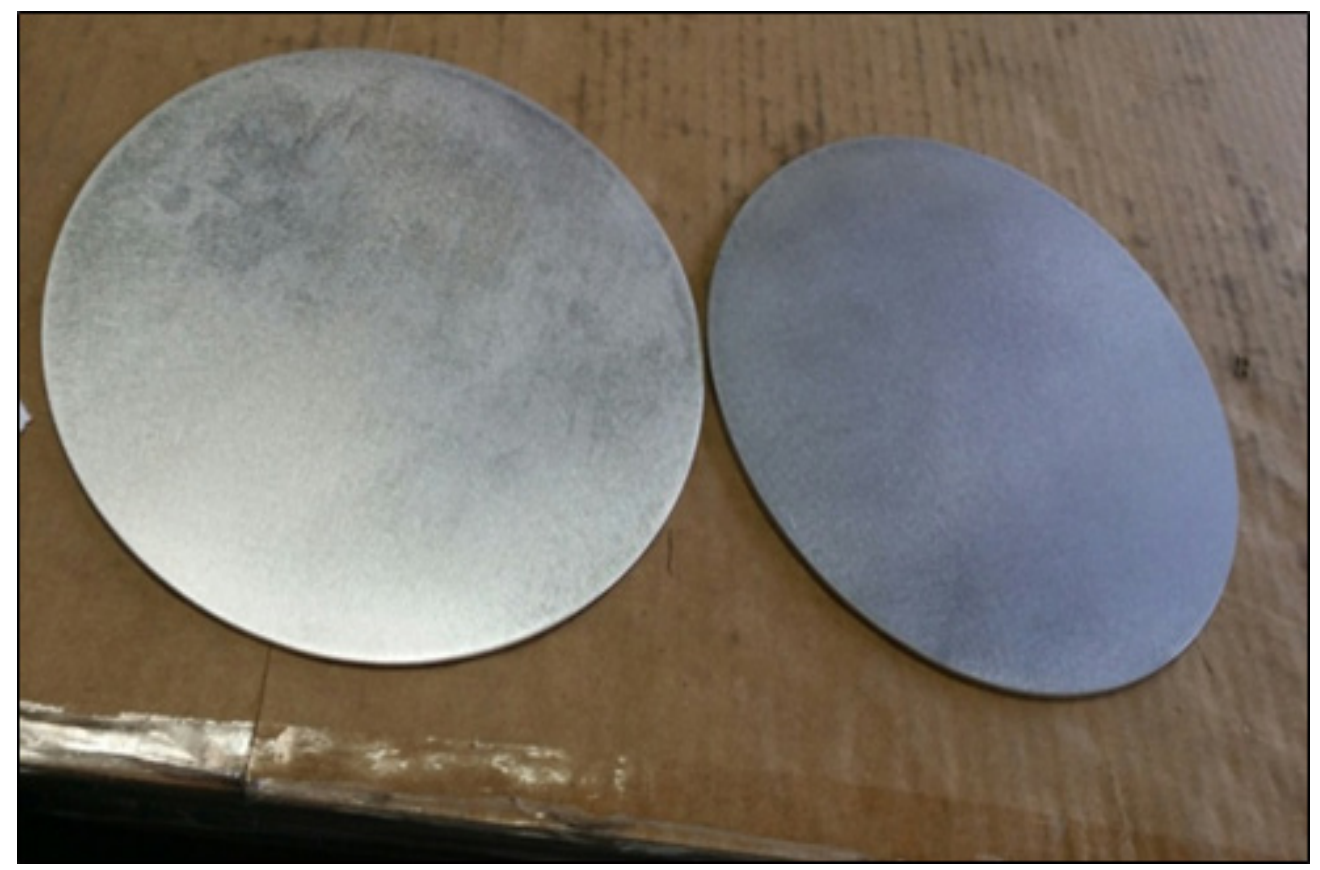

Figure 3. Arrangements of aluminium plates.

the main frame bed, which has narrow horizontal spaces, lined with the silicon wipers. When each component of the plates gets pushed, they are moving forward till they complete the process. The analysis of their movement is conceptual that they are the vital process of the entire set up.

Figure 3 shows the arrangements of aluminum plates, Owing to its process of arrangement and the linear movement, all the plates get ensured that they are completed for that particular instance. This process of serial and consistent movement at regular intervals make sure that minimal amount of electric energy is consumed by the system according to the conservation of energy concept $\frac{5}{}$.

Procedural steps to be followed in the measure of plates are given below:

Step 4: Initially pneumatic actuator pushes the plate in to the frame

Step-3: Secondly the plates are on the frame

Step-2: Thirdly the spraying step takes place

Step-1: Finally the heating operation in the air blower chamber occurs

\section{Alternate Mode of Commuting the Circular Plates}

As a part of our study, we have analyzed that commuting the plates with the help of a multi belt conveyor will also serve its purpose. But unfortunately, we are dealing with the wet flux mixture over the circular plates, we found that this is not feasible, and it affects the output efficiency and the overall time consumption in the operation.

\section{Vertical Arrangement of the Air Atomizer}

Air atomizers (sprayers) are the vital component in this automated flux application system. The specially designed sprayer that has more efficiency is selected for the operation. The flux that is mixed with the required amount of water is stored in the tank of the sprayer, in which constant mixing is done. This process of consistent in the clock-wise rotation mixing of the flux mixture helps to retain its consistency and helps to form an even coating on the aluminum plates. Over a period of time, they are 


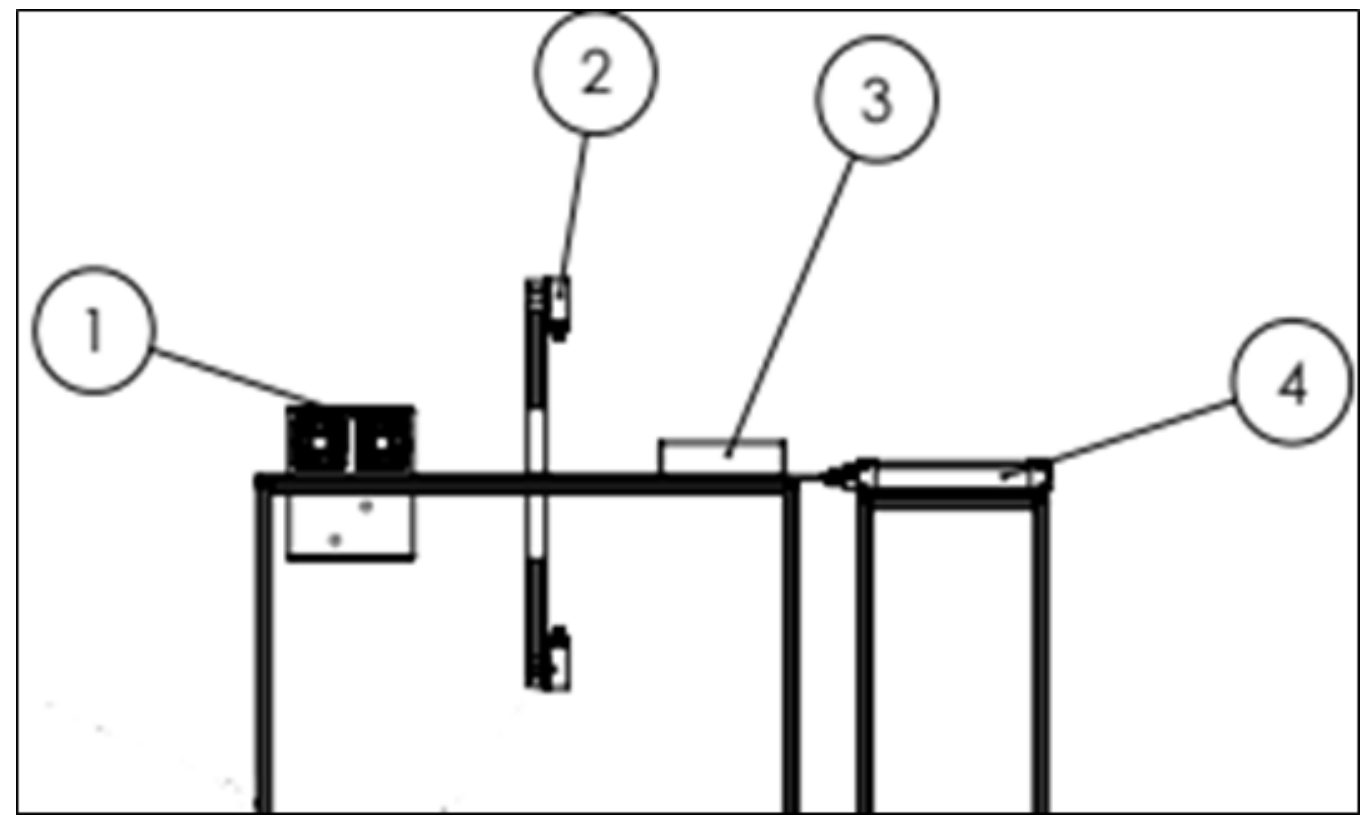

Figure 4. Steps of serial movement from 4 to 1 .

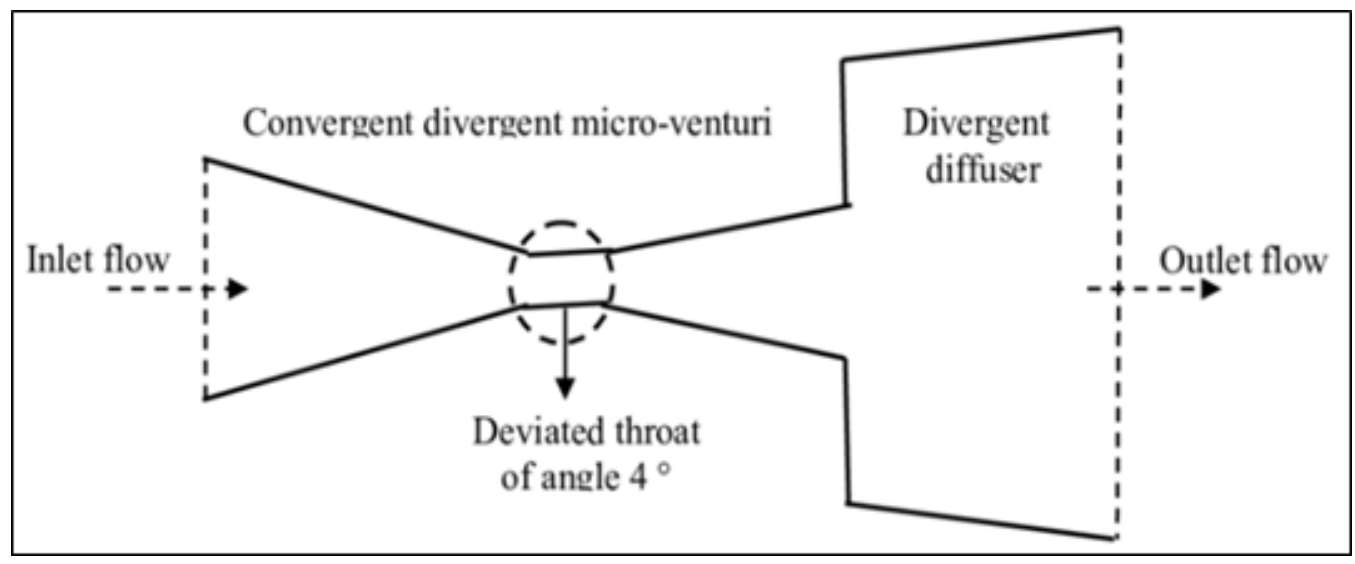

Figure 5. Geometry of the atomizer nozzle.

more organized and working towards the programmed length, so that the direction is unique for each and every size (diameter) of the plates shows in Figure 4-5.

\section{Control Systems}

The microcontroller is the central controlling unit in which the input is given by the interfacing device (key- board) and the output is obtained in the liquid crystal display panel. Figure 6 gives the block diagram of preliminary electrical system. There are four relay connections, connected with the micro controller and each relay regulates specific operations ${ }^{6}$. Three relays bother the operation of the solenoid valve and one regulates the motor in the tank, which is used for stirring the flux mix- 


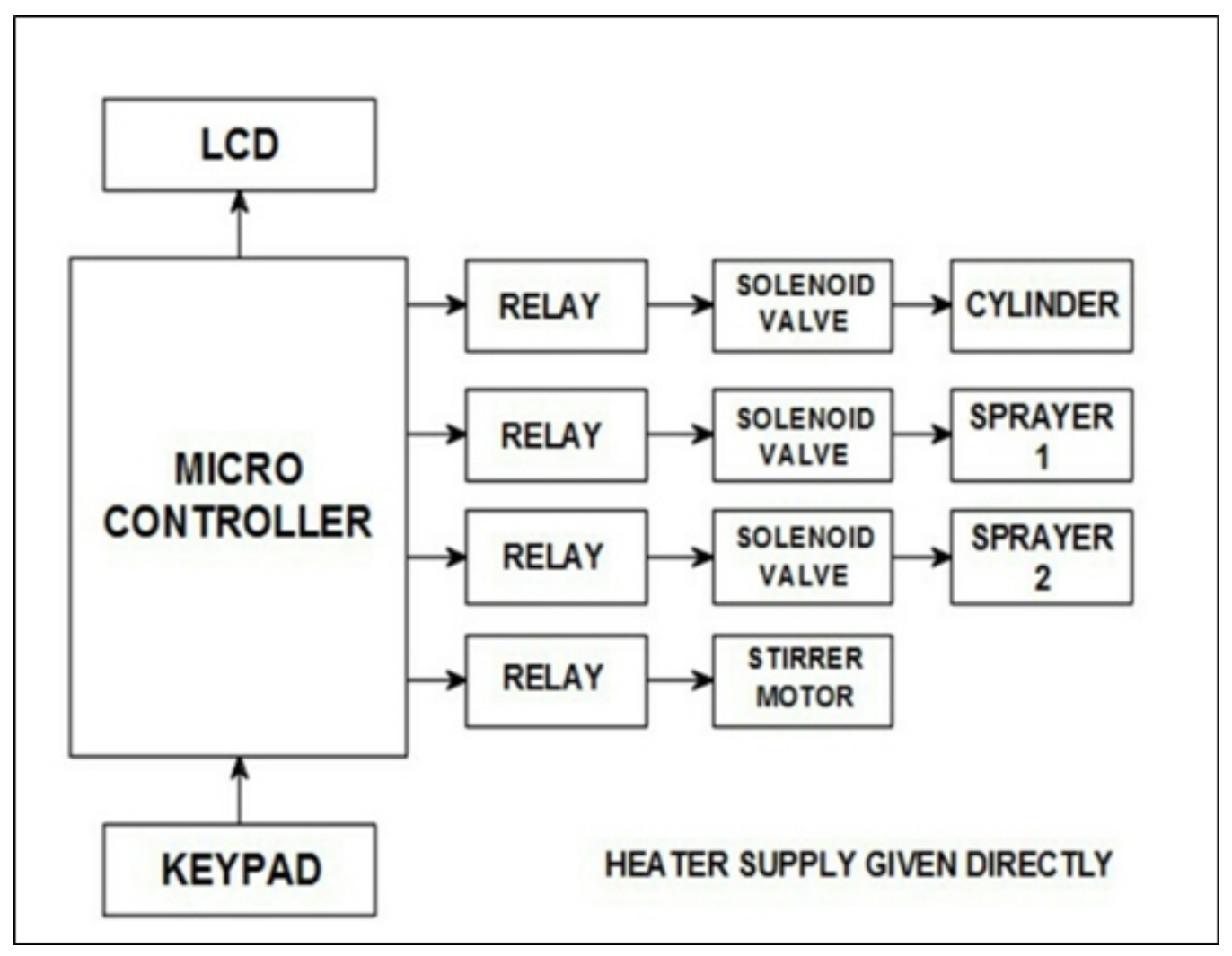

Figure 6. Block diagram of preliminary electrical system.

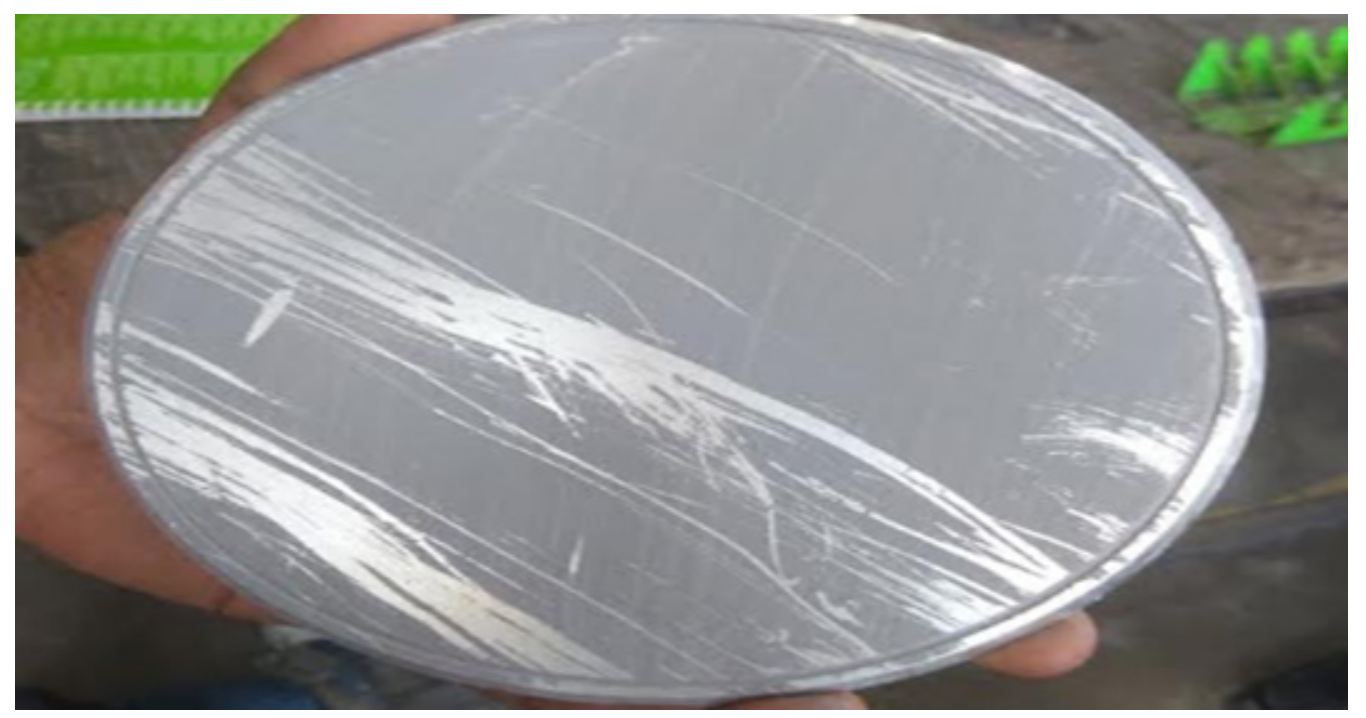

Figure 7. Meshing of flux layer due to wetness . 


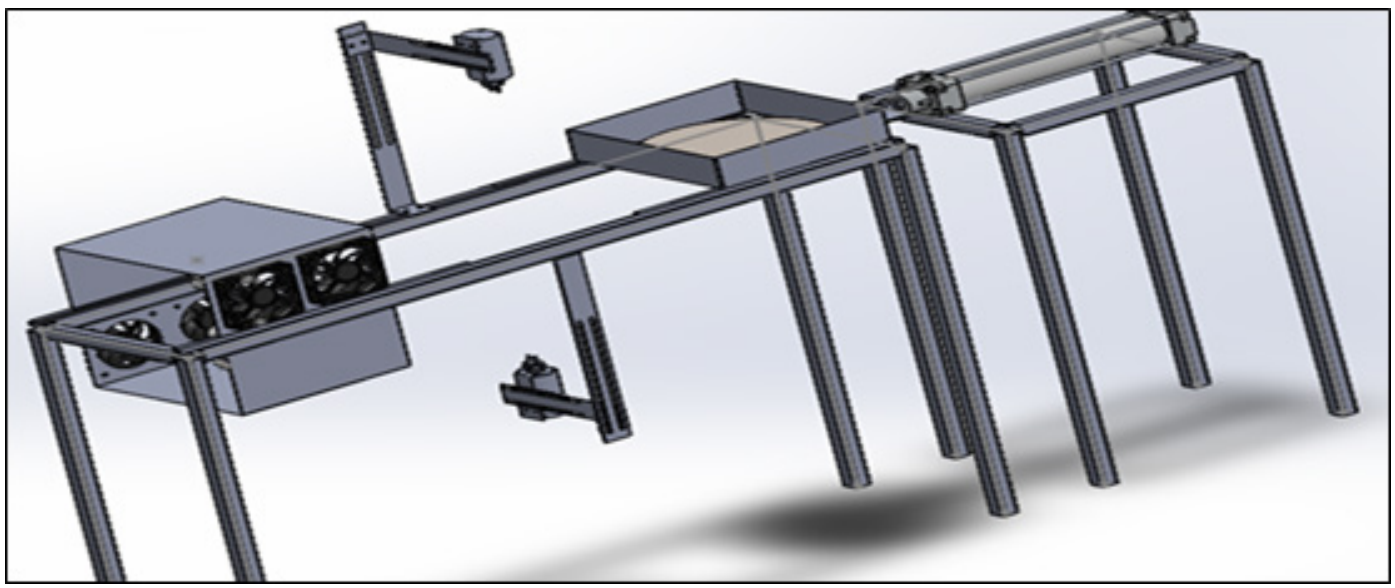

Figure 8. Side view of the overall system focusing vertical air blowers.

ture. The three solenoid valves: 1,2, 3 send the signal to the cylinder, sprayer 1 (top air atomizer) and sprayer 2 (bottom air atomizer) respectively.

\section{Heating the Wet Flux with Air Blowers}

The process of heating the wet flux layer helps to retain the applied layer of the flux till the brazing operation is carried on ${ }^{7}$. The minimal amount of electricity is taken in order to heat the heating coils of the system and then they release constant heat energy in the form of waves ${ }^{8}$. This process of convectional heating of the plates is very significant. Study and analysis is done in order to not affect the chemical properties of the flux layer and the aluminum plates so that the output efficiency is not compromised $\stackrel{9-11}{\text {. }}$.

\section{Adjustments of the Air Blowers for Varied Aluminium Plate Diameters}

In the industry, various aluminum plates with different sizes are used for the flux application process. In order to satisfy that feature the height adjustments have been made for the spraying chambers as well as the heating units. Once the height of the particular components is adjusted, they work for that stipulated diameter. For instance, very short distance is maintained between the plates and the components in case if smaller plates and notably larger distance is maintained for the larger diameter plates.

\section{Result and Discussion}

The automatic spray coating system will help in the industries to do spray coating very easily and it will be very useful for the industrial technological up gradation. We come to conclude that, automatic spray coating techniques to reduce the overall cost of the spray coating system.

\section{Conclusion}

The entire process of atomizing makes the minimal and no human labours involved in the operation of the flux application in the industries. Owing to its consequences of handling hazardous chemicals manually and due to the fly ash concept the human laborers may affect biologically. Also due to the automation of the entire process, the mass manufacturing can be done very easily and effectively.

\section{Acknowledgment}

We thank our associates from department of Mechatronics Engineering at Sri Krishna College of Engineering and 
Technology who provided insight and expertise that significantly assisted the research, although they may not agree with all of the interpretations of this article.

\section{References}

1. David SA. Advances in Welding Science and Technology. ASM International, Materials Park, Ohio; 1996. p. 1-15.

2. Gussone J, Kasperovich G, Haubrich J, Requena G. Interfacial reactions and fracture behavior of $\mathrm{Ti}$ Alloy$\mathrm{Ag} 28 \mathrm{Cu}$ brazing joints: Influence of titanium alloy composition, Metals. 2018; 8:830. https://doi.org/10.3390/ met8100830.

3. Meengam C, Dunyakul Y, Maunkhaw D, Chainarong S. Transient liquid phase bonding of semi-solid metal 7075 aluminum alloy using ZA27 zinc alloy interlayer, Metals. 2018; 8:1-13. https://doi.org/10.3390/met8080637.

4. Garcia J. Brazeability of Aluminum Alloys Containing Magnesium by CAB Process Using Cesium Flux. Society of Automotive Engineers, Inc.; 2001. p. 1-11. https://doi. org/10.4271/2001-01-1763.

5. Cooke W, Bowman A. Tunnel furnace brazing of aluminum using a non-corrosive flux, Welding Journal. 1980.
6. Meurer C, Lauzon DC, K^nig, H.: Stability of R-134a in the Presence of NOCOLOKÆ Flux Residues. SAE Technical Paper \# 980052, Warrendale, PA; 1997. https://doi. org/10.4271/980052.

7. Registration Record of International Alloy Designations and Chemical Composition Limits for Wrought Aluminum and Wrought Aluminum Alloys, The Aluminum Association, Inc.; 1998. p. 27.

8. Okamoto I, Takemoto T. Brazability of aluminum using Al-Si filler alloys with different compositions and microstructures, Transactions of JWRI. 1981; 10(2).

9. Piquet $\mathrm{O}$. The RF design of the Linac $4 \mathrm{RFQ}$, International Particle Accelerator Conference; 2010. p. MOPD027.

10. Song CW, Lee SY. Design of a solenoid actuator with a magnetic plunger for miniaturized segment robots, Applied Science. 2015; 5:595-607. https://doi.org/10.3390/ app5030595.

11. Jadhav KD, Dhanvijay MR. Design and standardization of base frame and ant vibration mounts for balanced opposed piston air compressor, International Journal of Applied Research in Mechanical Engineering. 2012; 2(2):1-8. 